\title{
The dynamic analysis of rotors mounted on composite shafts with internal damping
}

\author{
Willy Roger De Paula Mendonça*, Everton Coelho De Medeiros, Artur Luiz Rezende Pereira, \\ Mauro Hugo Mathias \\ Universidade Estadual Paulista “Júlio de Mesquista Filho”, Campus de Guaratinguetá, Av. Doutor Ariberto Pereira da Cunha, 333, 12516-410 Guaratinguetá, SP, Brazil
}

\section{A R T I C L E I N F O}

\section{Article history:}

Received 24 July 2014

Revised 28 January 2017

Accepted 30 January 2017

Available online 1 February 2017

\section{Keywords:}

Critical speed

Finite element

Loss factor

Viscoelastic

Damping

Classical laminate theory

\begin{abstract}
A B S T R A C T
This paper presents a study on the dynamic analysis of rotors mounted on composite shafts. The dynamic analysis of these rotors differs from conventional analysis due to the existence of internal damping in the shaft. The shafts are made of composite materials, which exhibit viscoelastic behavior. The equations of motion for these rotors represent the influence of internal damping on the dynamic behavior of the rotor system. Composite materials can be manufactured using different layups. This study reviews the methodology that can be used to predict the equivalent mechanical properties of composite shafts. Several finite element simulations are presented to show the influence of the composite shaft layup on the dynamic behavior of the rotor. The simulation results are used to present the influence of the layup on Campbell diagrams, critical speeds, instability thresholds and frequency response functions.
\end{abstract}

(c) 2017 Elsevier Ltd. All rights reserved.

\section{Introduction}

Recent decades have seen the increasing use of composite materials in engineering applications. Among these materials, carbon fiber composites have been used in the naval, military, aerospace and automotive industries [1,2]. This increase is due to their excellent mechanical properties, such as high strength-toweight ratios, very high ratios of the modulus of elasticity to weight, high fatigue strength [3], light weight, good corrosion resistance and very low coefficients of thermal expansion. Some of these properties are highly relevant to the development of rotating machinery, especially for rotor shafts under fatigue and high torque [3]. Several studies have used composite materials to improve the efficiency of rotating machinery [4,5]. Some current applications include drive shafts in helicopters, ships and cars [6-8].

The design of rotor axes or other structures, such as helicopters blades and wind turbine rotors, need to be carefully design because to high levels of oscillatory loads [9]. The designer can optimize the structure by adjusting the mechanical properties of the composite material through the choice of an appropriate layup. These properties affect the dynamic behavior of the rotor by changing the nat-

\footnotetext{
* Corresponding author.

E-mail address: eng.willy.mendonca@gmail.com (W.R. De P. Mendonça).
}

ural frequency and, consequently, the critical speed and instability threshold [10].

Carbon fiber composites are classified as viscoelastic materials, which have high internal damping compared to metallic materials. The existence of this damping, turns the prediction of natural frequencies difficult instead of using static stiffness [11]. In a rotor system, the presence of damping from an external source, such as certain types of bearings, is beneficial because damping promotes stability [12]. The opposite situation occurs when the damping occurs in the rotor shaft. Although shaft damping may reduce the vibration amplitude at subcritical speeds, instability often occurs in the rotor at supercritical speeds. Because many rotating machines operate at supercritical speeds, it is necessary to characterize the dynamics of composite shafts to make such applications possible. Different methods have demonstrated that it is possible to choose lamination sequences that increase the critical speed of a shaft, often extending the range of stable operating conditions $[13,14]$.

As in $[7,15]$, this paper uses classical laminate theory (CLT) to predict the internal damping and Young's modulus of composite shafts. A dynamic analysis is performed of rotors with internal damping; this analysis differs from the traditional approach for rotors because the viscoelastic material properties are a function of many parameters, such as the frequency of excitation and temperature [16]. The hygrothermal environment around the shaft also can influence the behavior and the properties in composite 
shafts, many studies are been carried out in this $[17,18]$. A series of numerical simulations is then performed to evaluate the influence of the laminate layup on the mechanical properties of the composite shaft; additional simulations demonstrate the influence of these properties on the dynamic behavior of the rotor. Finally, results are shown from rotor dynamic simulations of shafts made with different materials, including steel, aluminum, titanium and carbon fiber composite. These simulations can be related to a modal analysis of composites structures, like other authors presents [19,20].

The aim of this study is to improve the understanding of the dynamics of rotors with composite shafts through simulations based on existing methodologies, thus demonstrating the limits of technology and enabling the development of strategies to improve the selection of composite layups using optimization algorithms.

\section{Predicting the mechanical properties of composite shafts}

With increasing use of composite materials, there has been a growing interest in manufacturing process. There are many techniques, such as: hand lay-up, filament winding, pultrusion and resin transfer molding (RTM) [21]. Normally, these layers are wound on a cylindrical mandrel. Based on the Young's modulus of each ply, together with the direction and position of the plies in the stacking sequence, it is possible to predict the mechanical properties of a shaft.

CLT provides expressions for the calculation of the equivalent modulus of elasticity of a laminate [15]. This process is described in detail by Daniel and Ishai [5]. Fig. 1(a) shows a laminate tube and the global coordinate system adopted. Fig. 1(b) shows the laminate for which the properties are estimated. The total thickness of the laminate $(t)$ is obtained from the difference between the external radius $(\mathrm{Re})$ and the inner radius ( $\mathrm{Ri}$ ) of the tube. Fig. 1(c) illustrates the local and global fiber coordinate systems. The coordinate transformation is performed as a function of the angle $\theta$ between these systems.

From the CLT are known relations to obtain the equivalent modulus of elasticity for thin-walled laminates as demonstrated by Daniel and Ishai [22]. For a unidirectional lamina under plane stress state the relation stress=strain to an especially orthotropic lamina is:

$\{\sigma\}=[S]^{-1}\{\varepsilon\}=[Q]\{\varepsilon\}$

where

$$
[S]=\left[\begin{array}{ccc}
\frac{1}{E_{1}} & -\frac{v_{21}}{E_{1}} & 0 \\
-\frac{v_{12}}{E_{1}} & \frac{1}{E_{2}} & 0 \\
0 & 0 & \frac{1}{G_{12}}
\end{array}\right] \text { and }[Q]=\left[\begin{array}{ccc}
\frac{E_{1}}{1-v_{12} v_{21}} & \frac{v_{12} E_{2}}{1-v_{12} v_{21}} & 0 \\
\frac{v_{12} E_{2}}{1-v_{12} v_{21}} & \frac{E_{2}}{1-v_{12} v_{21}} & 0 \\
0 & 0 & G_{12}
\end{array}\right]
$$

the subscript 1 and 2 take reference to coordinate system of fiber as illustrate in Fig. 1.

The transformation to the laminate coordinate system is obtained by:

$[\bar{Q}]=[T]^{-1}[Q][T]^{-T}$

where

$[T]=\left[\begin{array}{ccc}m^{2} & n^{2} & 2 m n \\ n^{2} & m^{2} & -2 m n \\ -m n & m n & m^{2}-n^{2}\end{array}\right]$ and $\mathrm{m}=\cos \theta, \mathrm{n}=\sin \theta$.

The resulting efforts in the plane are related to the deformation of the median plane by expression:

$\left[\begin{array}{l}N \\ M\end{array}\right]=\left[\begin{array}{ll}A & B \\ B & D\end{array}\right]\left[\begin{array}{l}\varepsilon^{0} \\ \kappa\end{array}\right]$

where $\mathrm{N}$ and $\mathrm{M}$ are stress and moment resultants per unit length, $\varepsilon$ and $\kappa$ are strains and curvature, at the mid-plane.

The matrices $A, B$ and $D$ are extensional stiffiness, coupling stiffiness and bending stiffiness respectively, which are calculate as:

$A_{i j}=\sum_{k=1}^{n} Q_{i j}^{k}\left(h_{k}^{-} h_{k-1}\right)$

$B_{i j}=\frac{1}{2} \sum_{k=1}^{n} Q_{i j}^{k}\left(h_{k}^{2}-h_{k-1}^{2}\right)$

$D_{i j}=\frac{1}{3} \sum_{k=1}^{n} Q_{i j}^{k}\left(h_{k}^{3}-h_{k-1}^{3}\right)$

with $\mathrm{i}, \mathrm{j}=\mathrm{x}, \mathrm{y}, \mathrm{s}$ and $\overline{\mathrm{Q}}_{i j}^{k}$ is reduced stiffiness matrix for each ply.

In this work the equivalent modulus of laminate was obtained as:

$$
\begin{aligned}
E_{x} & =\frac{1}{t a_{x x}}, \quad E_{y}=\frac{1}{t a_{y y}}, \quad G_{x y}=\frac{1}{t a_{s s}}, \quad v_{x y}=-\frac{a_{y x}}{a_{x x}}, \quad v_{y x} \\
& =-\frac{a_{x y}}{a_{y y}}
\end{aligned}
$$

where $a_{i j}$ is the compliance matrix obtained from inverse of matrix $[A B D]$.

Several studies describe the methodology for calculating the equivalent modulus of laminated tubes using CLT [23,24]. Besides of CLT, other procedures like dimensional reduction method based on polynomials and Rayleigh-Ritz method is presented by other author to obtain the cross-sectional properties [25,26].

In this work, the evaluation of the specific damping capacity (SDC) is based on the formulation developed by $\mathrm{Ni}$ and Adams

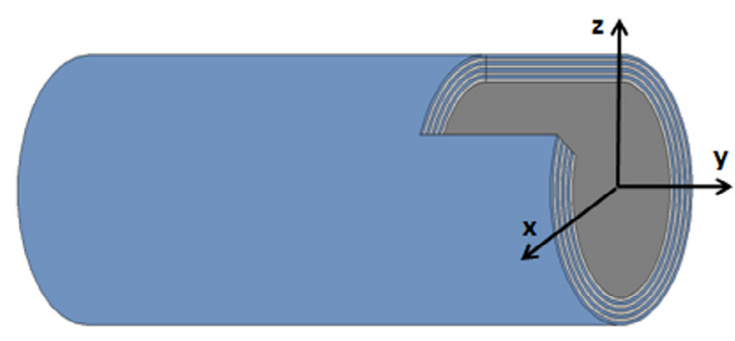

A)

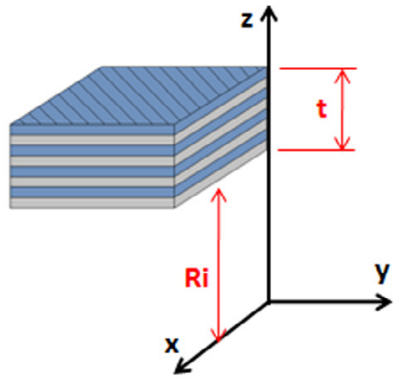

B)

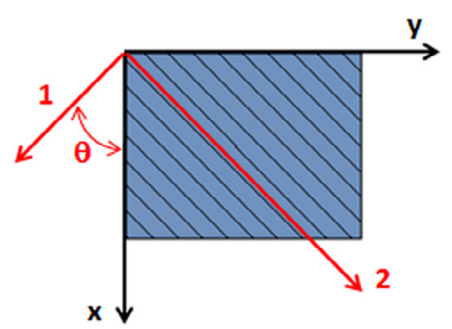

c)

Fig. 1. Coordinate systems. 
[27], which uses CLT to obtain the equivalent damping of the laminate. The total damping in Eq. (10) is the sum of the directional components derived using Eqs. (11)-(13).

$\psi_{\text {laminate }}=\psi_{x}+\psi_{y}+\psi_{x y}$

$\psi_{x}=\frac{2 \psi_{1}}{3 d_{11}} \sum_{k=1}^{p}\left(Q_{x x}^{k} d_{x x}+Q_{x y}^{k} d_{x y}+Q_{s s}^{k} d_{s s}\right)\left(m_{k}^{2} d_{x x}+m_{k} n_{k} d_{s s}\right)\left(h_{k}^{3}-h_{k-1}^{3}\right) m_{k}^{2}$

$\psi_{y}=\frac{2 \psi_{2}}{3 d_{11}} \sum_{k=1}^{p}\left(Q_{x x}^{k} d_{x x}+Q_{x y}^{k} d_{x y}+Q_{s s}^{k} d_{s s}\right)\left(n_{k}^{2} d_{x x}-m_{k} n_{k} d_{s s}\right)\left(h_{k}^{3}-h_{k-1}^{3}\right) n_{k}^{2}$

$$
\begin{aligned}
\psi_{x y}= & \frac{2 \psi_{12}}{3 d_{11}} \sum_{k=1}^{p}\left(Q_{x x}^{k} d_{x x}+Q_{x y}^{k} d_{x y}+Q_{s s}^{k} d_{s s}\right)\left(2 m_{k} n_{k} d_{x x}-m_{k}^{2} n_{k}^{2} d_{s s}\right) \\
& \times\left(h_{k}^{3}-h_{k-1}^{3}\right) m_{k} n_{k}
\end{aligned}
$$

Consider a multilayered composite shaft made of "P" orthotropic layers. If the layup is symmetric the shaft has a typical beam behavior and can be modeled by using classical beam theory associated the homogenized stiffness parameters. If the layup is non-symmetric, mechanical coupling effects such as bendingstretching, twisting-stretching and shear-stretching will be present $[10,28]$. In this article the effects due to couplings were neglected.

\section{Dynamic analysis of a rotor with internal damping}

Viscoelastic materials, such as the rotors used in this study, experience high internal damping compared to metallic materials. This behavior is due to the composite constituents: carbon fiber exhibits elastic behavior and epoxy resin possesses viscous behavior [16]. Understanding the influence of the internal damping [11] of the shafts on the dynamic behavior of the rotor is essential for proper design and application to provide the mechanical benefits already described. Therefore, it is necessary to use a detailed mathematical model that considers the effect of internal damping in the shaft on the rotor's dynamic behavior. The [29] presents ways for determine the damping parameters, using measurements techniques applied in laminated composite materials.

Dynamic rotor analysis differs from the traditional analysis due to the damping of the rotating components, which is due to two internal dynamic mechanisms. The first mechanism is energy dissipation, which occurs in each cycle of the shaft as the shaft is subjected to alternating stresses. Due to internal damping, the elastic modulus of the material can be represented mathematically in complex form [30]. This behavior is represented by the damping matrix $[\mathrm{Cr}]$ in Eq. (14). The second mechanism is the transfer of energy from the spinning system to vibration. This behavior is represented by the circulatory matrix $[\mathrm{H}]$ in Eq. (14). This mechanism is proportional to the rotational speed of the rotor.

\subsection{Equations of motion}

According to Genta [31], the general equation of motion presented in Eq. (14) in the complex form is valid when the displacements and unbalance are small, allowing the equation of motion to be linearized and maintaining consistency with conventional structural dynamics. In this equation of motion, the rotor is considered axially symmetric to the axis of rotation, which rotates at a constant speed $\Omega$ r.

$[M] \ddot{x}(t)+\left[C_{\mathrm{n}}+\eta C_{\mathrm{r}}-\mathrm{iG}\left(\Omega_{\mathrm{r}}\right)\right] \dot{x}(t)+\left[\mathrm{K}-\mathrm{i} \eta \mathrm{H}\left(\Omega_{\mathrm{e}}\right)\right] x(t)=f(t)$
The Eq. (14) represents a class of rotors whose axis produces internal damping, where $\{x(t)\}$ is a vector of generalized coordinates; $[\mathrm{M}]$ is the symmetric mass matrix; $\left[C_{n}\right]$ is the symmetric damping matrix for the non-rotating structures, such as bearings; $\left[\mathrm{C}_{\mathrm{r}}\right]$ is the damping matrix for the elements of the rotating axis; $[\mathrm{G}(\Omega \mathrm{r})]$ is the skew-symmetric gyroscopic matrix related to the rotational speed of the rotor; $[\mathrm{K}]$ is the symmetric stiffness matrix; $\left[\mathrm{H}\left(\Omega_{\mathrm{e}}\right)\right]$ is the anti-symmetric circulatory matrix, which is dependent on the excitation frequency; $\{\mathrm{f}(\mathrm{t})\}$ is a time-dependent vector that contains all of the forces acting on the system; and $\eta$ is the loss factor associated with the internal damping of the shaft [29]. These matrices are widely used in the literature, except for $\left[C_{\mathrm{r}}\right]$ and $\left[\mathrm{H}\left(\Omega_{\mathrm{e}}\right)\right]$, which are related to the matrix $[\mathrm{K}]$ : $\left[\mathrm{C}_{\mathrm{r}}\right]$ is identical to $[\mathrm{K}]$, and $\left[\mathrm{H}\left(\Omega_{\mathrm{e}}\right)\right]$ is anti-symmetric to $[\mathrm{K}]$. (15).

Eq. (14) can be written in the state space form as shown in Eq.

$[A]\{\dot{q}(t)\}+[B]\{q(t)\}=\{f(t)\}$,

where matrices $\mathrm{A}$ and $\mathrm{B}$ are

$[A]=\left[\begin{array}{cc}{\left[C_{\mathrm{n}}+\eta C_{r}+G\left(\Omega_{r}\right)\right]} & {[M]} \\ {[M]} & {[0]}\end{array}\right], \quad[B]=\left[\begin{array}{cc}{\left[\mathrm{K}+\eta H\left(\Omega_{\mathrm{e}}\right)\right]} & {[0]} \\ {[0]} & -[M]\end{array}\right]$

and the state vector $\mathrm{q}(\mathrm{t})$ and force vector $\mathrm{F}(\mathrm{t})$ are

$$
\{F(t)\}=\left\{\begin{array}{c}
\{f(t)\} \\
\{0\}
\end{array}\right\}, \quad\{q(t)\}=\left\{\begin{array}{c}
\dot{x}(t) \\
x(t)
\end{array}\right\}
$$

\subsection{Free vibration analysis}

To carry out a free vibration analysis of the system, it is necessary to determine the eigenvalues and their associated eigenvectors [32-34]. Through the eigenvalues, it is possible to evaluate the natural frequencies, the damping parameters and the rotor stability and to generate the Campbell diagram, which shows the critical speeds of the rotor. The vibration modes and orbits are obtained from the eigenvectors. Due to the existence of antisymmetric matrices in Eq. (16), unlike in conventional eigenvalue analysis, the adjoint problem must also be solved. The solution shown in Eq. (18) is assumed:

$q(t)=\Phi \cdot e^{s t}$

For free vibration, $\{\mathrm{F}(\mathrm{t})\}=0$ and

$q(t)=\left\{\begin{array}{c}\dot{x}(t) \\ x(t)\end{array}\right\} \Rightarrow \Phi=\left\{\begin{array}{c}s \phi \\ \phi\end{array}\right\}$

Eq. (15) can be rewritten as

$[S[A]+[B]] \Phi=\{0\}, \quad$ with $\lambda=-s=-j \Omega$

The existence of the anti-symmetric matrices $\left[\mathrm{G}\left(\Omega_{\mathrm{r}}\right)\right]$ and $[\mathrm{H}$ $\left.\left(\Omega_{e}\right)\right]$ results in two eigenvectors, called the right and left eigenvectors, as shown in Eq. (21).

$[B] \cdot \Phi_{\mathrm{i}}=\lambda_{i} \cdot[A] \cdot \Phi_{i}$ and $[B]^{T} \cdot \Psi_{\mathrm{i}}=\lambda_{\mathrm{i}}[\mathrm{A}]^{\mathrm{T}} \cdot \Psi_{\mathrm{i}}$

where $\lambda_{\mathrm{i}}$ is the eigenvalue

$\Phi_{i}=\left\{\begin{array}{c}\lambda_{i}\{\phi\}_{i} \\ \{\phi\}_{i}\end{array}\right\}$ is the righteigen vector

$\Psi_{i}=\left\{\begin{array}{c}\lambda_{i}\{\psi\}_{i} \\ \{\psi\}_{i}\end{array}\right\}$ is the lefteigen vector

The modal matrices are obtained by organizing the eigenvectors into columns. Note that there are two systems for the rotation modal matrices, one right $[\Phi]$ and the other left $[\Psi]$. 
$[\Phi]=\left[\Phi_{1} ; \Phi_{2} ; \ldots ; \Phi_{N}\right]$

$[\Psi]=\left[\Psi_{1} ; \Psi_{2} ; \ldots ; \Psi_{N}\right]$

The eigenvectors may be orthonormalized using the relationships in Eq. (26). For orthonormalization, the diagonal matrix [a] $=[\Psi]^{\mathrm{T}}[\mathrm{A}][\Phi]$ is used.

$\Phi_{i} / \sqrt{a_{i}}$ and $\Psi_{i} / \sqrt{a_{i}}$

Using this transformation, it is possible to verify the properties expressed in Eqs. (27) and (28).

$[\Psi]^{T}[A][\Phi]=[I]$

$[\Psi]^{T}[B][\Phi]=[\Lambda]$

where $[\mathrm{I}]$ is the identity matrix and $[\Lambda]$ is a diagonal matrix of the eigenvalues.

\subsection{Campbell diagram}

The Campbell diagram may be generated in two ways, depending on the type of excitation applied to the rotor. These two methods were explored by Espindola and Floody [35]. Eq. (14) shows that the rotor equation of motion is dependent on its spin speed $(\Omega r)$ and excitation frequency $(\Omega e)$. In the first case, where $\Omega \mathrm{e} \neq \Omega \mathrm{r}$, an auxiliary Campbell diagram $(\mathrm{Fn} \times \Omega \mathrm{e})$ is created for each rotor spin speed. The natural frequencies are determined from a straight line obtained from the equality $F n=\Omega$. These natural frequencies are used to generate the final Campbell diagram (Fn $\times \Omega r$ ). Fig. 2 shows the construction of the final Campbell diagram; two auxiliary diagrams are presented for rotations of 200 and $600 \mathrm{rev} / \mathrm{min}$.

In the second case, where $\Omega \mathrm{e}=\Omega \mathrm{r}$, a simplified Campbell diagram is constructed according to Espíndola and Bavastri [36]. In this case, the excitation is due to an imbalance, so the excitation frequency is equal to the rotor spin speed. Eq. (14) becomes dependent on a single frequency, so that the Campbell diagram is obtained in a single step, similar to the creation of the auxiliary Campbell diagram.

\subsection{Unbalance excitation and the frequency response function}

The unbalance is used to demonstrate the methodology for the frequency response function (FRF). In this case, $\Omega e=\Omega_{\mathrm{r}}$. The $\mathrm{q}(\mathrm{t})$ coordinates in the state vector of Eq. (15) are determined from a linear combination of the right eigenvector- $\Phi$ modal coordinates multiplied by $\mathrm{p}_{\mathrm{i}}(\mathrm{t})$, as shown in Eq. (29).

$q(t)=\sum_{i=1}^{N} \phi_{i} \cdot p_{i}(t)=[\Phi] \cdot \mathrm{p}(\mathrm{t})$

Substituting this relation into Eq. (15) and pre-multiplying by the transpose of the left eigenvector, the following equation is obtained.

$[\Psi]^{T} \cdot[A] \cdot[\Phi] \cdot \dot{p}(t)+[\Psi]^{T} \cdot[B] \cdot[\Phi] \cdot p(t)=[\Psi]^{T} \cdot f(t)$

Combining the orthonormalization properties from Eqs. (27) and (28) with Eq. (15) gives

$[\mathrm{I}] \cdot \dot{p}(t)+[\Lambda] \cdot p(t)=n(t)$

where $n(t)=[\Psi]^{T} \cdot f(t)$ is the modal excitation vector. Eq. (31) describes a group of independent modal equations that can be represented as in Eq. (32) for a specific mode:

$\dot{p}_{\mathrm{i}}(t)+\lambda_{\mathrm{i}} p_{i}(t)=n_{i}(t)$

Using the Fourier transform, Eq. (32) is transformed to the frequency domain, taking the form shown in Eq. (33).

$(j \Omega[I]+[\Lambda]) \cdot P(\Omega)=[\Psi]^{T} F(\Omega)$

Rearranging the expression gives

$P(\Omega)=\frac{[\Psi]^{T} \cdot F(\Omega)}{j \Omega[I]+[\Lambda]}$

After conversion to the state space using the relation in Eq. (29), the expression takes the form

$Q(\Omega)=\frac{[\Phi][\Psi]^{T} \cdot F(\Omega)}{j \Omega[I]+[\Lambda]}$

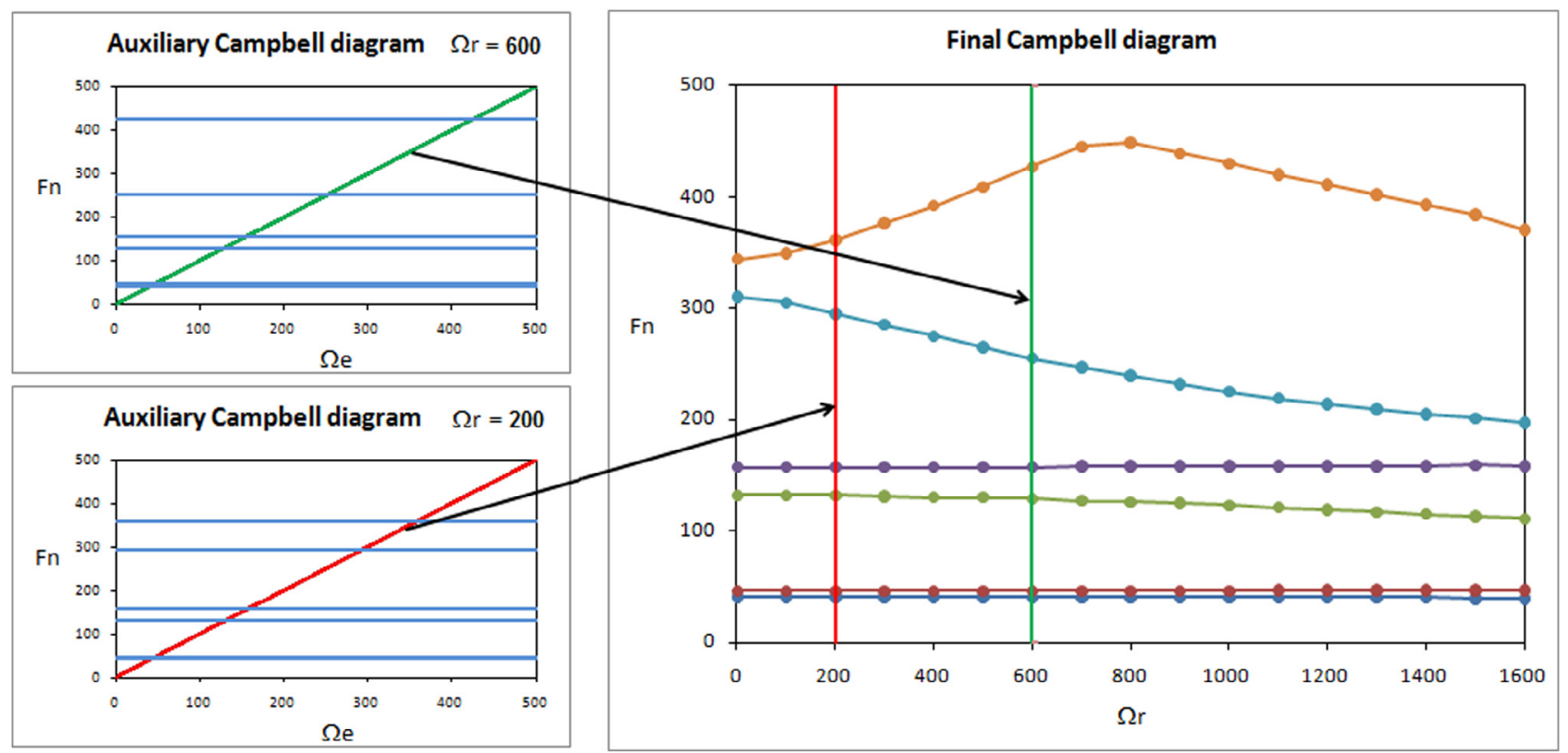

Fig. 2. Final and auxiliary Campbell diagrams 
This can be represented in compact form as

$Q(\Omega)=[\alpha(\Omega)] \cdot F(\Omega)$

The matrix $[\alpha(\Omega)]$ is the receptance matrix, also known as the characteristic matrix of the system. This matrix has complex coefficients, which are frequency dependent. Each term of the receptance matrix represents a relationship between a measurement point, designated by the index s, and an excitation point, represented by the index $\mathrm{k}$.

$\alpha_{k s}(\Omega)=\sum_{i=1}^{2 N} \frac{\phi_{k i} \psi_{s i}^{T}}{j \Omega+\lambda_{i}}$

Fig. 3 shows the case in which the excitation frequency is not due to unbalance. In this case, a frequency response is calculated for each rotor spin speed.

\subsection{Finite element model}

All results presented in this paper were obtained using the finite element method. Three basic elements were modeled, as illustrated in Fig. 4. The shafts were modeled with a constant section using two-node Rayleigh beam elements with four degrees of freedom: $\left\{\mathrm{u}_{1}, \mathrm{w}_{1}, \theta_{1}, \psi_{1}, \mathrm{u}_{2}, \mathrm{w}_{2}, \theta_{2}, \psi_{2}\right\}$, been $\mathrm{u}$ and $\mathrm{w}$ the axial displace- ments in the $\mathrm{x}$ and $\mathrm{z}$ directions, $\theta$ and $\psi$ the slopes about the $\mathrm{x}$ and $z$ axis. The displacement field is described as:

$u_{x}(x, y, z)=u(y)$

$u_{y}(x, y, z)=-z \theta_{x}(y)+x \psi_{z}(y)$

$u_{x}(x, y, z)=w(y)$

Thus the deformation field may be written as follows:

$\varepsilon_{y y}=-z \frac{\partial \theta_{x}}{\partial y}+x \frac{\partial \psi_{z}}{\partial y}$

$\gamma_{y z}=-\theta_{x}+z \frac{\partial w}{\partial y}$

$\gamma_{y x}=\psi_{z}+z \frac{\partial u}{\partial y}$

This formulation takes into account the effect of the rotary inertia, translational inertia, gyroscopic moments and rotational stiffness and the stationary and rotational damping forces [37,38]. Other way to simulate these models, is to describe the shaft with Timoshenko beam elements, this element provide a complete behavior and effects due to rotary inertia and shear effect, many works use this element [39-41].

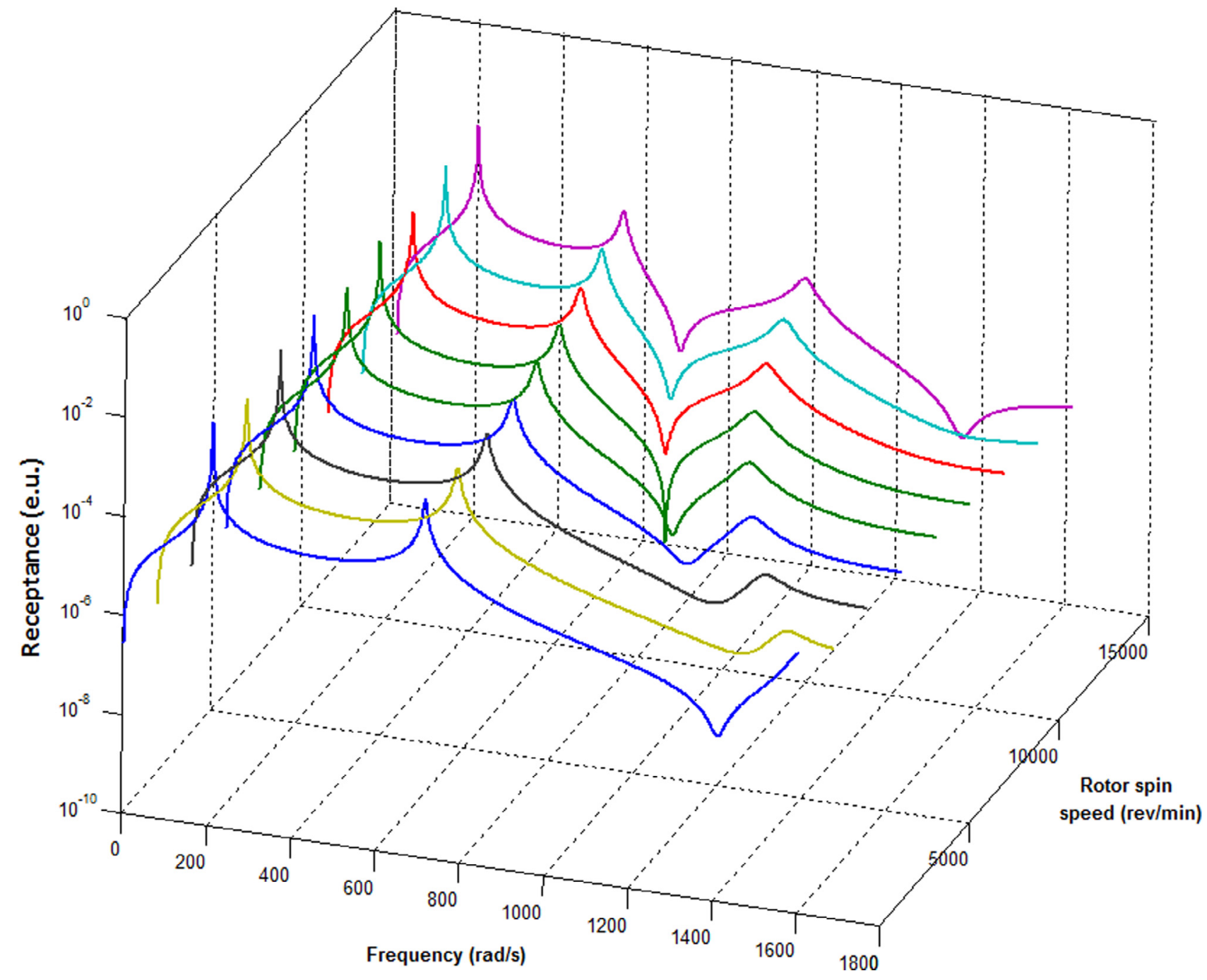

Fig. 3. The frequency response function for several rotor spin speeds. 


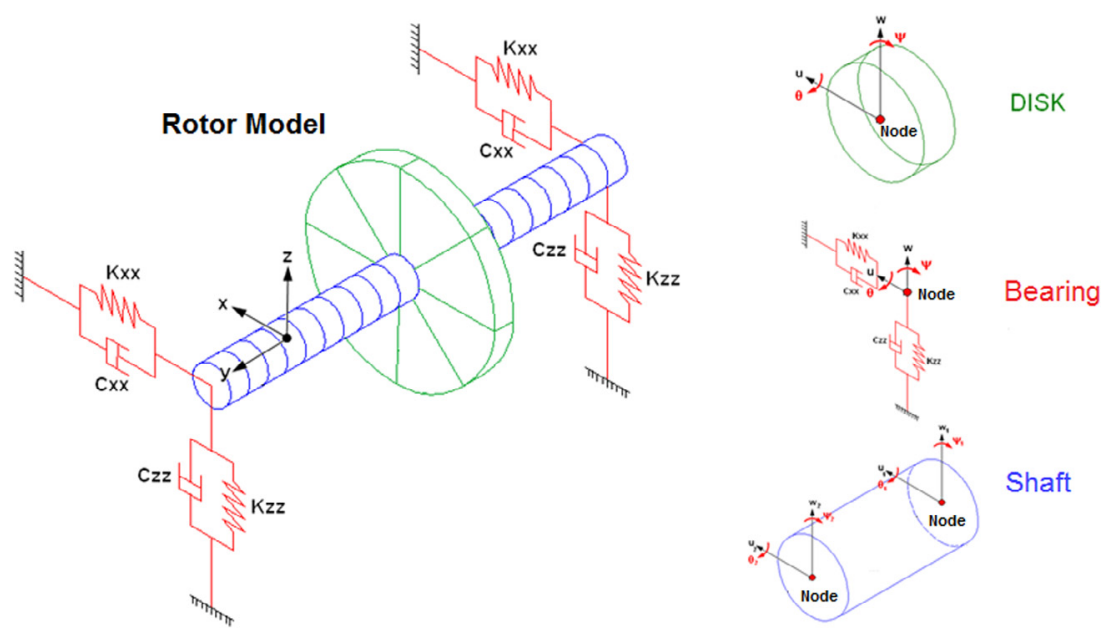

Fig. 4. Finite element model.

\section{Numerical simulations}

All simulated results were obtained using the reference model illustrated in Fig. 5. Table 1 shows the mechanical properties of the two carbon fiber composites used in the simulations.

\subsection{Influence of the layup on the mechanical properties of composite} shafts

In the layup of composite shafts, the sequence, quantity and orientation of the plies influence the mechanical properties of the laminate and, therefore, the dynamic behavior of the rotor. In this section, simulation results demonstrate these influences [42].

The first simulation evaluated the influence that the position of a pair of plies in the layup sequence has on the overall mechanical properties. Four simulations were performed in which the position of a pair of plies oriented at $\pm 75^{\circ}$ was varied within the layup sequence. The results are shown in Table 2.

The results demonstrate that the elastic modulus is independent of the position of the plies in the layup sequence. However, the SDC is not independent of the ply configuration.

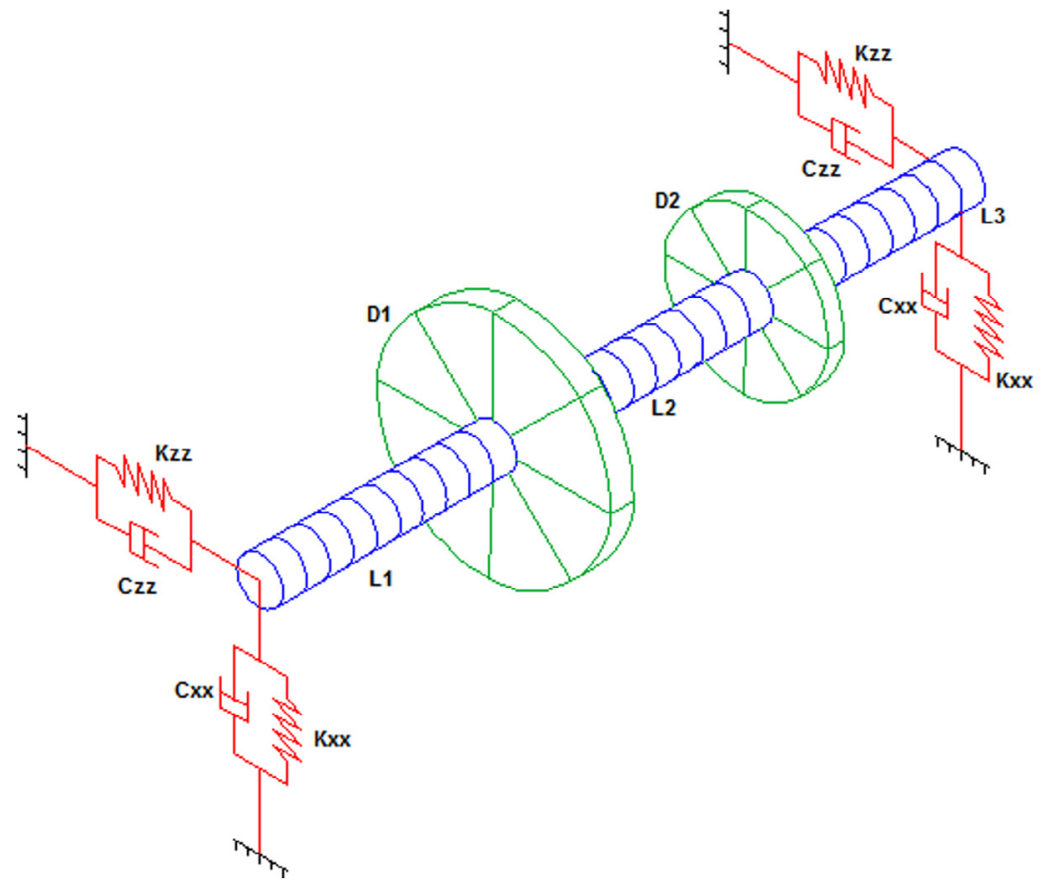

\begin{tabular}{|c|c|c|}
\hline \multicolumn{3}{|c|}{ Rotor } \\
\hline $\mathrm{L} 1=$ & 0.400 & $\mathrm{~m}$ \\
\hline $\mathrm{L} 2=$ & 0.400 & $\mathrm{~m}$ \\
\hline $\mathrm{L} 3=$ & 0.400 & $\mathrm{~m}$ \\
\hline $\mathrm{Ri}=$ & 0.040 & $\mathrm{~m}$ \\
\hline $\mathrm{Re}=$ & 0.048 & $\mathrm{~m}$ \\
\hline
\end{tabular}

\begin{tabular}{|ccc|}
\hline \multicolumn{3}{|c|}{ Bearings } \\
\hline $\mathrm{Kxx}=1.0 \mathrm{E} 7$ & $\mathrm{~N} / \mathrm{m}$ \\
\hline $\mathrm{Kzz}=1.0 \mathrm{E} 8$ & $\mathrm{~N} / \mathrm{m}$ \\
\hline $\mathrm{CXX}=0.000$ & $\mathrm{~N} / \mathrm{m} / \mathrm{s}$ \\
\hline $\mathrm{Czz}=0.000$ & $\mathrm{~N} / \mathrm{m} / \mathrm{s}$ \\
\hline
\end{tabular}

\begin{tabular}{|r|r|c|}
\hline \multicolumn{3}{|c|}{ Disk 1 } \\
\hline $\mathrm{Ri}=$ & 0.048 & $\mathrm{~m}$ \\
\hline $\mathrm{Re}=$ & 0.200 & $\mathrm{~m}$ \\
\hline $\mathrm{h}=$ & 0.050 & $\mathrm{~m}$ \\
\hline
\end{tabular}

\begin{tabular}{|r|r|c|}
\hline \multicolumn{3}{|c|}{ Disk 2 } \\
\hline $\mathrm{Ri}=$ & 0.048 & $\mathrm{~m}$ \\
\hline $\mathrm{Re}=$ & 0.150 & $\mathrm{~m}$ \\
\hline $\mathrm{h}=$ & 0.050 & $\mathrm{~m}$ \\
\hline
\end{tabular}

Fig. 5. The reference rotor model for the simulations.

Table 1

The materials properties used in the simulations.

\begin{tabular}{|c|c|c|c|c|c|c|c|}
\hline Material & $\mathrm{E}_{1}[\mathrm{GPa}]$ & $\mathrm{E}_{2}[\mathrm{GPa}]$ & $\mathrm{G}_{12}[\mathrm{GPa}]$ & $\mathrm{v}_{12}$ & $\psi_{1}[\%]$ & $\psi_{2}[\%]$ & $\psi_{12}[\%]$ \\
\hline HMS carbon-epoxy (DX-210) & 172.7 & 7.2 & 3.76 & 0.3 & 0.45 & 4.22 & 7.05 \\
\hline Fibredux 913C & 112.5 & 8.4 & 4.8 & 0.3 & 0.74 & 7.3 & 6.6 \\
\hline
\end{tabular}


Table 2

The mechanical properties of shafts with layer pairs in different positions.

\begin{tabular}{|c|c|c|c|c|c|c|c|}
\hline \multicolumn{8}{|c|}{ MATERIAL: HMS carbon-epoxy (DX-210) } \\
\hline Layup & $\mathrm{E}_{\mathrm{x}}$ & $\mathrm{E}_{\mathrm{y}}$ & $\mathrm{G}_{\mathrm{xy}}$ & $\psi_{\mathrm{x}}$ & $\psi_{\mathrm{y}}$ & $\psi_{\mathrm{xy}}$ & $\psi_{\mathrm{t}}$ \\
\hline & [GPa] & [GPa] & [GPa] & [\%] & [\%] & [\%] & {$[\%]$} \\
\hline$[75,-75,0,0,0,0,0,0]$ & 131.58 & 43.29 & 6.28 & 0.443 & 0.058 & 0.014 & 0.515 \\
\hline$[0,0,75,-75,0,0,0,0]$ & 131.58 & 43.29 & 6.28 & 0.444 & 0.051 & 0.012 & 0.508 \\
\hline$[0,0,0,0,75,-75,0,0]$ & 131.58 & 43.29 & 6.28 & 0.444 & 0.045 & 0.011 & 0.501 \\
\hline$[0,0,0,0,0,0,75,-75]$ & 131.58 & 43.29 & 6.28 & 0.445 & 0.040 & 0.010 & 0.495 \\
\hline
\end{tabular}

Several simulations were performed to predict the mechanical properties of off-axis and angle-ply laminate configurations. The simulations were performed for two materials. The results are grouped in Tables 3 and 4. In the last four configurations presented in these tables, the results demonstrate the same behavior shown in Table 2.

For the off-axis and angle-ply stacking sequences, it was possible to determine the variation in the mechanical properties as a function of the orientation of the plies. Fig. 6 shows the results for the elastic modulus, and Fig. 7 shows the results for the SDC. The differences between the off-axis and angle-ply results can be observed in Fig. 6; the off-axis configuration has greater variation in the elastic modulus and less variation in the shear modulus. Fig. 7 shows that the maximum damping occurs at different angles in the two materials. This is due to the distinct damping properties of the materials. In Table 2, it can be seen that in the first material, the $\psi_{12}$ damping component is greater than the other components.

\subsection{Layup influence on the rotor dynamic behavior}

Several parameters are used to dynamically characterize a rotor, the most important of which are the critical speed and the instability threshold [43]. In this section, simulations are described that demonstrate the influence of the layup on the rotor dynamic

Table 3

Predicted mechanical properties.

\begin{tabular}{|c|c|c|c|c|c|c|c|c|}
\hline \multicolumn{9}{|c|}{ MATERIAL: HMS carbon-epoxy (DX-210) } \\
\hline \multirow[t]{2}{*}{ Layup } & & $\mathrm{E}_{\mathrm{x}}$ & $\mathrm{E}_{\mathrm{y}}$ & $G_{x y}$ & $\psi_{\mathrm{x}}$ & $\psi_{\mathrm{y}}$ & $\psi_{\mathrm{xy}}$ & $\psi_{\mathrm{t}}$ \\
\hline & & [GPa] & {$[\mathrm{GPa}]$} & [GPa] & {$[\%]$} & [\%] & {$[\%]$} & [\%] \\
\hline \multirow[t]{7}{*}{ Off-axis } & {$\left[0_{8}\right]$} & 172.70 & 7.20 & 3.76 & 0.450 & 0.000 & 0.000 & 0.450 \\
\hline & {$\left[15_{8}\right]$} & 45.31 & 7.28 & 4.23 & 0.112 & 0.207 & 4.947 & 5.266 \\
\hline & {$\left[30_{8}\right]$} & 16.35 & 7.83 & 5.63 & 0.054 & 0.885 & 4.719 & 5.658 \\
\hline & {$\left[45_{8}\right]$} & 9.82 & 9.82 & 6.75 & 0.039 & 1.745 & 3.525 & 5.309 \\
\hline & {$\left[60_{8}\right]$} & 7.83 & 16.35 & 5.63 & 0.016 & 2.719 & 2.260 & 4.994 \\
\hline & {$\left[75_{8}\right]$} & 7.28 & 45.31 & 4.23 & 0.002 & 3.729 & 0.795 & 4.526 \\
\hline & {$\left[90_{8}\right]$} & 7.20 & 172.70 & 3.76 & 0.000 & 4.220 & 0.000 & 4.220 \\
\hline \multirow[t]{5}{*}{ Angle-ply } & {$[ \pm 15]_{2 \mathrm{~s}}$} & 134.04 & 7.29 & 13.84 & 0.392 & 0.019 & 0.881 & 1.292 \\
\hline & {$[ \pm 30]_{2 \mathrm{~S}}$} & 44.97 & 8.20 & 33.99 & 0.253 & 0.264 & 2.644 & 3.161 \\
\hline & {$[ \pm 45]_{2 \mathrm{~s}}$} & 13.91 & 13.91 & 44.06 & 0.112 & 1.055 & 3.525 & 4.693 \\
\hline & {$[ \pm 60]_{2 \mathrm{~S}}$} & 8.20 & 44.97 & 33.99 & 0.028 & 2.374 & 2.644 & 5.046 \\
\hline & {$[ \pm 75]_{2 \mathrm{~s}}$} & 7.29 & 134.04 & 13.84 & 0.002 & 3.674 & 0.881 & 4.557 \\
\hline \multirow[t]{4}{*}{ Others } & {$[45,0,45,0,90,0,90,0]$} & 92.80 & 51.44 & 11.33 & 0.420 & 0.169 & 0.183 & 0.773 \\
\hline & {$[90,45,02]_{\mathrm{S}}$} & 92.80 & 51.44 & 11.33 & 0.421 & 0.166 & 0.170 & 0.757 \\
\hline & {$[90,0,90,45,90,45,0,90]$} & 51.44 & 92.80 & 11.33 & 0.382 & 0.454 & 0.309 & 1.145 \\
\hline & {$[902,45,0]_{S}$} & 51.44 & 92.80 & 11.33 & 0.382 & 0.454 & 0.314 & 1.149 \\
\hline
\end{tabular}

Table 4

Predicted mechanical properties.

\begin{tabular}{|c|c|c|c|c|c|c|c|c|}
\hline \multicolumn{9}{|c|}{ MATERIAL: HMS carbon-epoxy (DX-210) } \\
\hline \multirow[t]{2}{*}{ Layup } & & $\mathrm{E}_{\mathrm{x}}$ & $\mathrm{E}_{\mathrm{y}}$ & $G_{x y}$ & $\mathrm{Y}_{\mathrm{x}}$ & $\mathrm{Y}_{\mathrm{y}}$ & $Y_{x y}$ & $Y_{t}$ \\
\hline & & [GPa] & [GPa] & [GPa] & [\%] & [\%] & [\%] & [\%] \\
\hline \multirow[t]{7}{*}{ Off-axis } & {$\left[0_{8}\right]$} & 112.50 & 8.40 & 4.80 & 0.740 & 0.000 & 0.000 & 0.740 \\
\hline & {$\left[15_{8}\right]$} & 47.71 & 8.59 & 5.28 & 0.284 & 0.288 & 3.811 & 4.382 \\
\hline & {$\left[30_{8}\right]$} & 19.80 & 9.47 & 6.58 & 0.112 & 1.457 & 4.284 & 5.853 \\
\hline & {$\left[45_{8}\right]$} & 12.09 & 12.09 & 7.50 & 0.062 & 3.040 & 3.300 & 6.402 \\
\hline & {$\left[60_{8}\right]$} & 9.47 & 19.80 & 6.58 & 0.022 & 4.812 & 2.049 & 6.884 \\
\hline & {$\left[75_{8}\right]$} & 8.59 & 47.71 & 5.28 & 0.002 & 6.520 & 0.686 & 7.208 \\
\hline & {$\left[90_{8}\right]$} & 8.40 & 112.50 & 4.80 & 0.000 & 7.300 & 0.000 & 7.300 \\
\hline \multirow[t]{5}{*}{ Angle-ply } & {$[ \pm 5]_{2 S}$} & 92.22 & 8.64 & 10.89 & 0.644 & 0.033 & 0.825 & 1.502 \\
\hline & {$[ \pm 30]_{2 \mathrm{~S}}$} & 42.37 & 10.09 & 23.07 & 0.416 & 0.456 & 2.475 & 3.347 \\
\hline & {$[ \pm 45]_{2 \mathrm{~s}}$} & 16.67 & 16.67 & 29.16 & 0.185 & 1.825 & 3.300 & 5.310 \\
\hline & {$[ \pm 60]_{2 \mathrm{~S}}$} & 10.09 & 42.37 & 23.07 & 0.046 & 4.106 & 2.475 & 6.627 \\
\hline & {$[ \pm 75]_{2 \mathrm{~s}}$} & 8.64 & 92.22 & 10.89 & 0.003 & 6.355 & 0.825 & 7.183 \\
\hline \multirow[t]{4}{*}{ Others } & {$[45,0,45,0,90,0,90,0]$} & 63.35 & 37.38 & 9.45 & 0.663 & 0.457 & 0.275 & 1.395 \\
\hline & {$[90,45,02]_{\mathrm{S}}$} & 63.35 & 37.38 & 9.45 & 0.666 & 0.449 & 0.253 & 1.368 \\
\hline & {$[90,0,90,45,90,45,0,90]$} & 37.38 & 63.35 & 9.45 & 0.571 & 1.189 & 0.433 & 2.193 \\
\hline & {$[902,45,0]_{\mathrm{S}}$} & 37.38 & 63.35 & 9.45 & 0.570 & 1.190 & 0.440 & 2.200 \\
\hline
\end{tabular}



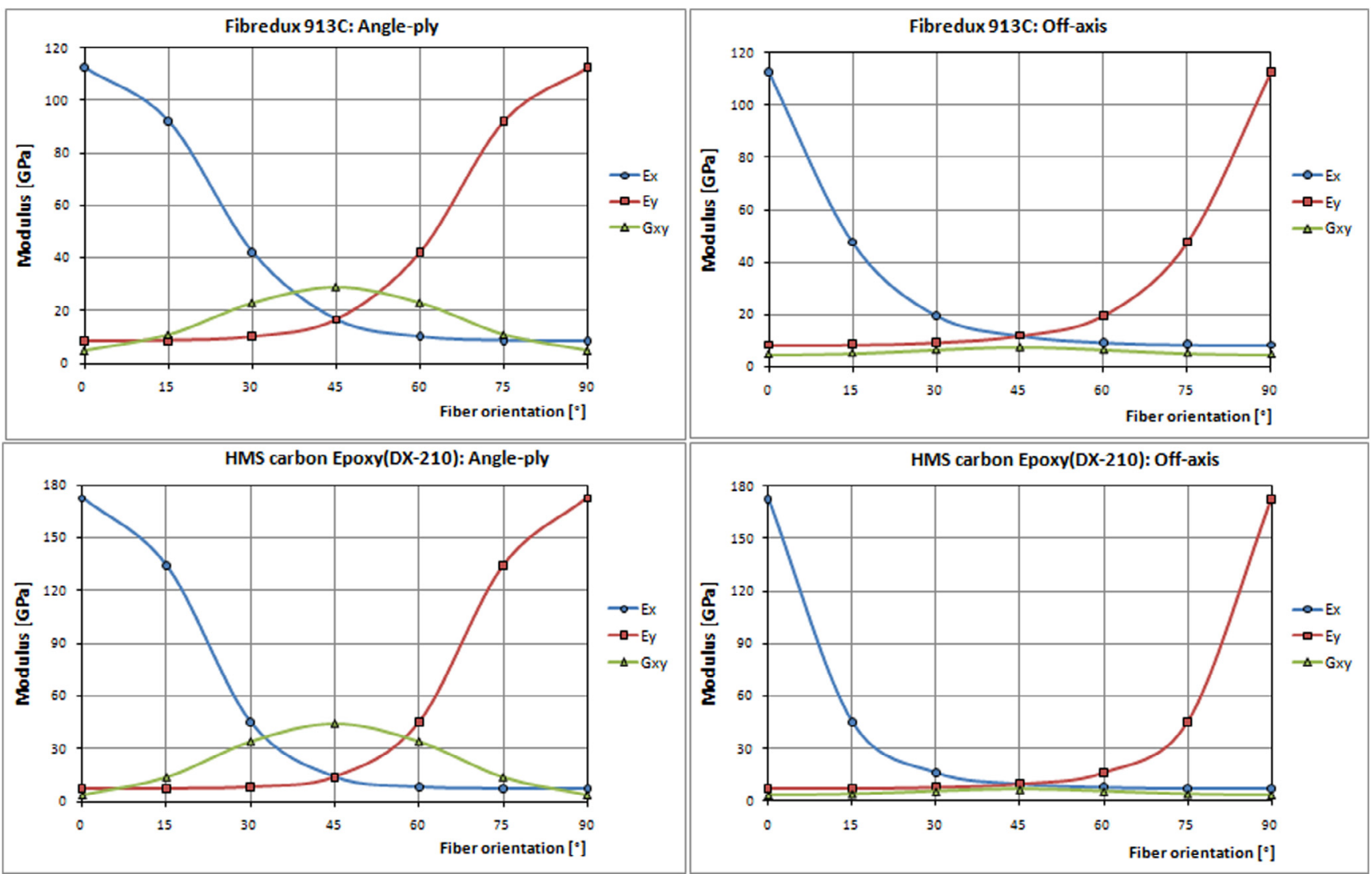

Fig. 6. Elastic modulus as a function of the fiber orientation.
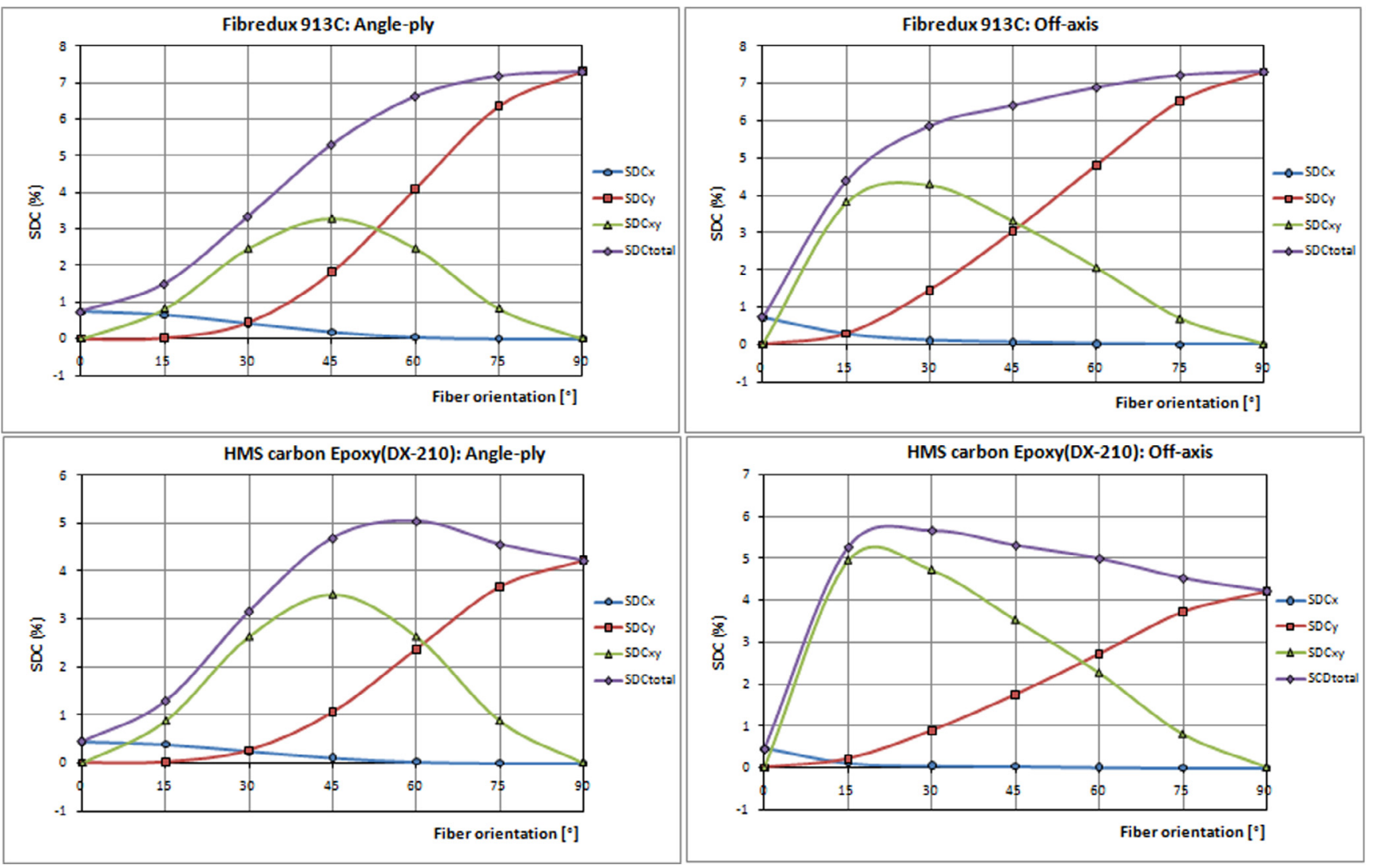

Fig. 7. SDC as a function of the fiber orientation. 
Table 5

Critical speeds and instability thresholds.

\begin{tabular}{|c|c|c|c|c|c|}
\hline \multicolumn{6}{|c|}{ MATERIAL: HMS carbon-epoxy (DX-210) } \\
\hline & \multirow[t]{2}{*}{ Layup } & Inst. Fw1 & Inst. Fw2 & Vc1 & Vc2 \\
\hline & & {$[\mathrm{rpm}]$} & {$[\mathrm{rpm}]$} & {$[\mathrm{rpm}]$} & {$[\mathrm{rpm}]$} \\
\hline \multirow[t]{7}{*}{ Off-axis } & {$\left[0_{8}\right]$} & 13,913 & $>15,000$ & 3065 & 7955 \\
\hline & {$\left[15_{8}\right]$} & 3676 & 7649 & 1996 & 6427 \\
\hline & {$\left[30_{8}\right]$} & 1537 & 5052 & 1232 & 4746 \\
\hline & {$\left[45_{8}\right]$} & 1079 & 3982 & 926 & 3829 \\
\hline & {$\left[60_{8}\right]$} & 1079 & 3676 & 926 & 3524 \\
\hline & {$\left[75_{8}\right]$} & 926 & 3371 & 926 & 3371 \\
\hline & {$\left[90_{8}\right]$} & 926 & 3371 & 926 & 3371 \\
\hline \multirow[t]{5}{*}{ Angle-ply } & {$[ \pm 15]_{2 \mathrm{~S}}$} & 12,538 & $>15,000$ & 3218 & 11010 \\
\hline & {$[ \pm 30]_{2 S}$} & 3676 & 9635 & 1996 & 8107 \\
\hline & {$[ \pm 45]_{2 \mathrm{~S}}$} & 1385 & 5052 & 1232 & 4822 \\
\hline & {$[ \pm 60]_{2 S}$} & 1079 & 3829 & 926 & 3676 \\
\hline & {$[ \pm 75]_{2 \mathrm{~S}}$} & 926 & 3524 & 926 & 3524 \\
\hline \multirow[t]{4}{*}{ Others } & {$[45,0,45,0,90,0,90,0]$} & 8170 & 13,149 & 2760 & 9482 \\
\hline & {$[90,45,02]_{\mathrm{S}}$} & 7955 & 13,149 & 2760 & 9482 \\
\hline & {$[90,0,90,45,90,45,0,90]$} & 4288 & 9482 & 2149 & 7802 \\
\hline & {$[902,45,0]_{\mathrm{S}}$} & 4440 & 9482 & 2149 & 7802 \\
\hline
\end{tabular}

behavior. The reference model in Fig. 5 was used for these simulations. To guarantee that the effects of the rotor instability were exclusively due to the internal damping in the shaft, no bearing damping was included. The excitation force in these models can be attributed only to unbalance.

Table 5 shows the results of the simulations performed. In the first column on the left, the layup sequences are listed. The second column contains the rotational speeds at which the system becomes unstable at the first natural frequency; the third column presents the same results for the second natural frequency. The fourth and fifth columns show the first and second critical velocities, respectively.

Some interesting observations can be made from the results in Table 5 . In both the off-axis and angle-ply configurations, as the ply angle increases, both the rotor instability threshold and critical speed decrease.

Figs. 8-11 show the Campbell diagrams from the rotor simulations. In the diagrams, four natural frequencies are plotted. The critical speeds were identified from the intersections of the curves, and the instability regions were obtained from the points of overlap with the natural frequency lines.

In Fig. 8, the regions of instability only occur above the first natural frequency. Figs. 8 and 9 show unstable regions for two natural frequencies. It can be observed in Fig. 10 that the instabilities occur immediately above the critical speeds. Comparing these results with those presented in Table 3, it can be seen that the greatest stability is obtained from the simulated model shown in Fig. 8. This is due to the lower damping $\left(\psi_{\mathrm{t}}=0.45 \%\right)$ associated with the high

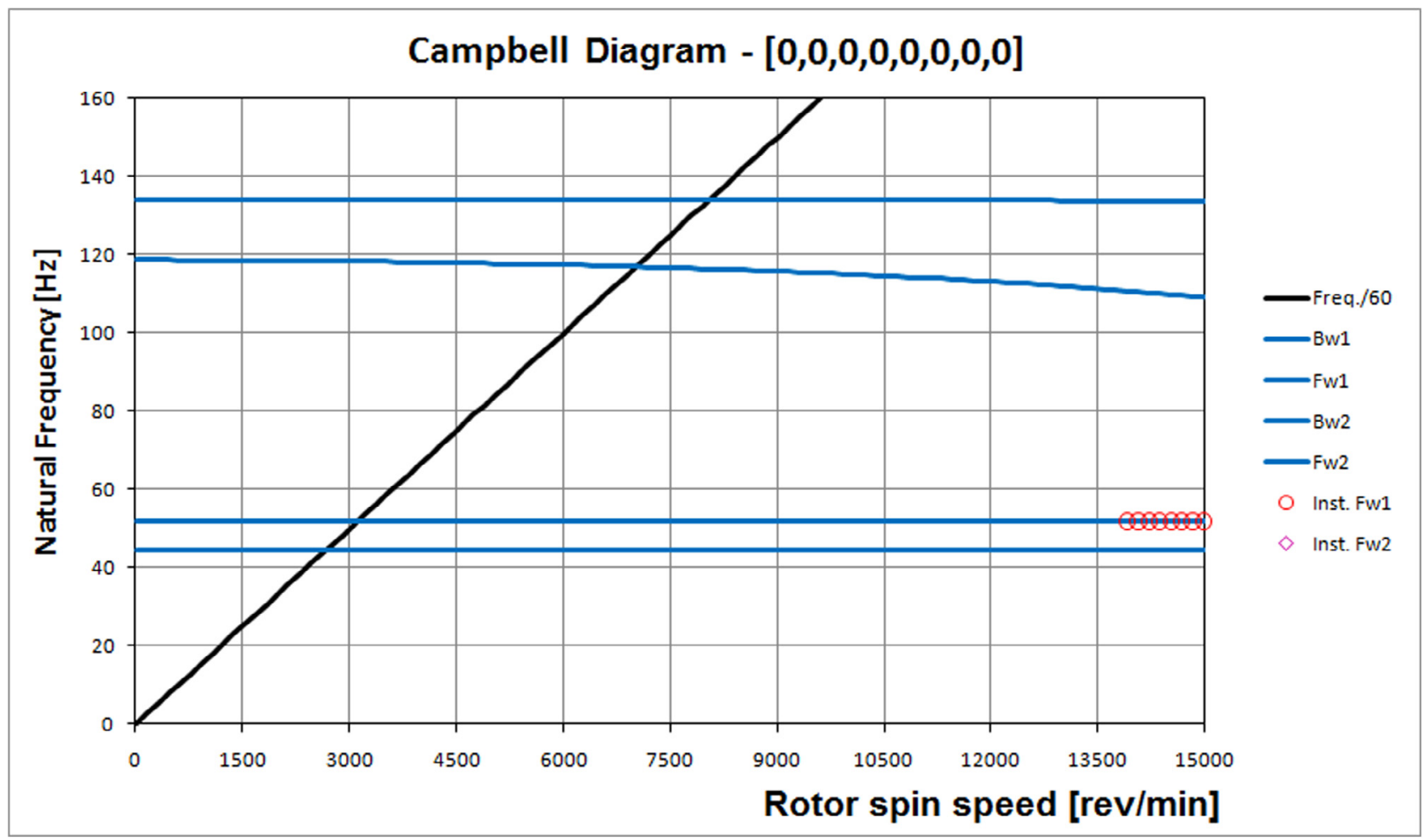

Fig. 8. Campbell diagram and instability regions for layup $[0,0,0,0,0,0,0,0]$. 


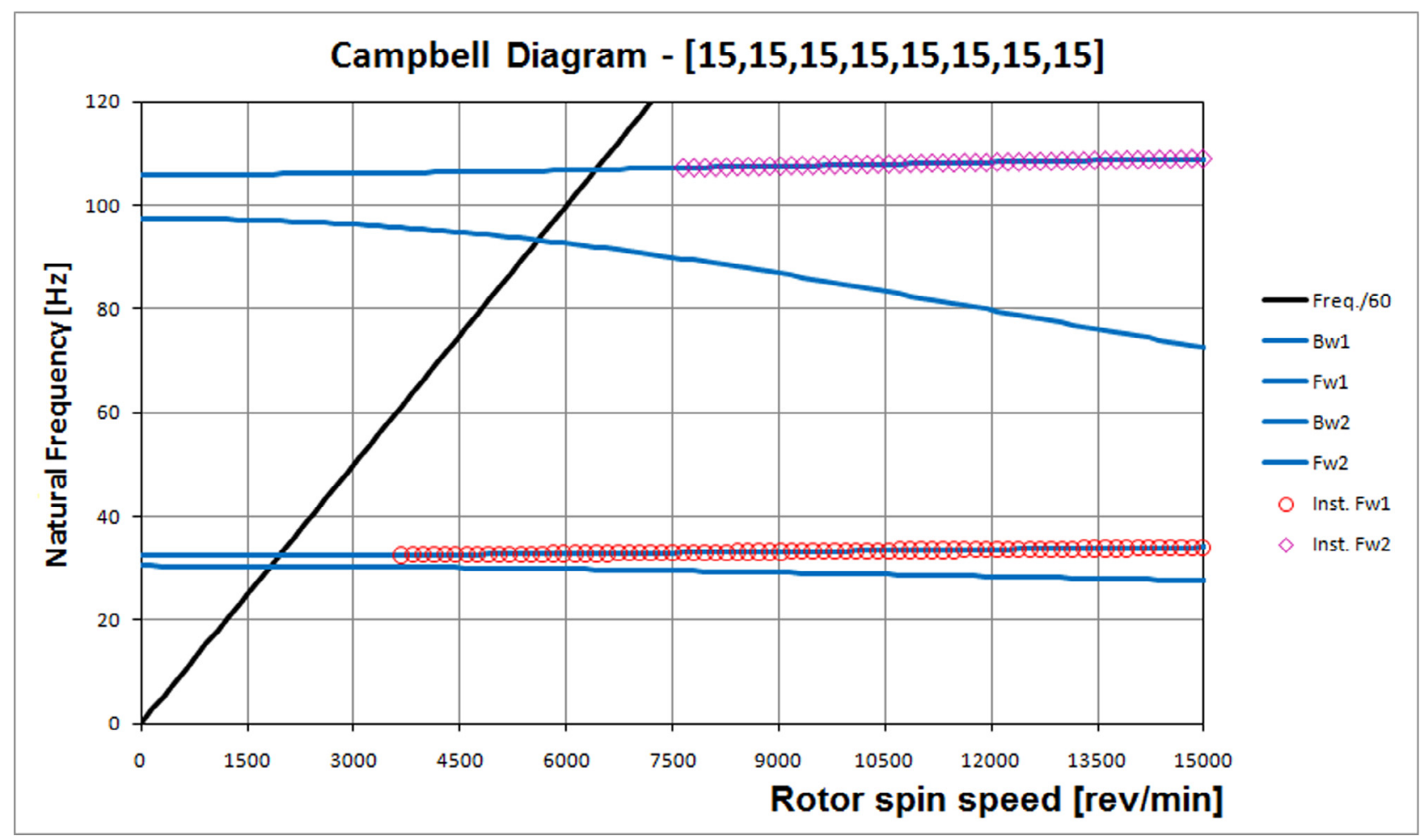

Fig. 9. Campbell diagram and instability regions for layup $[15,15,15,15,15,15,15,15]$.

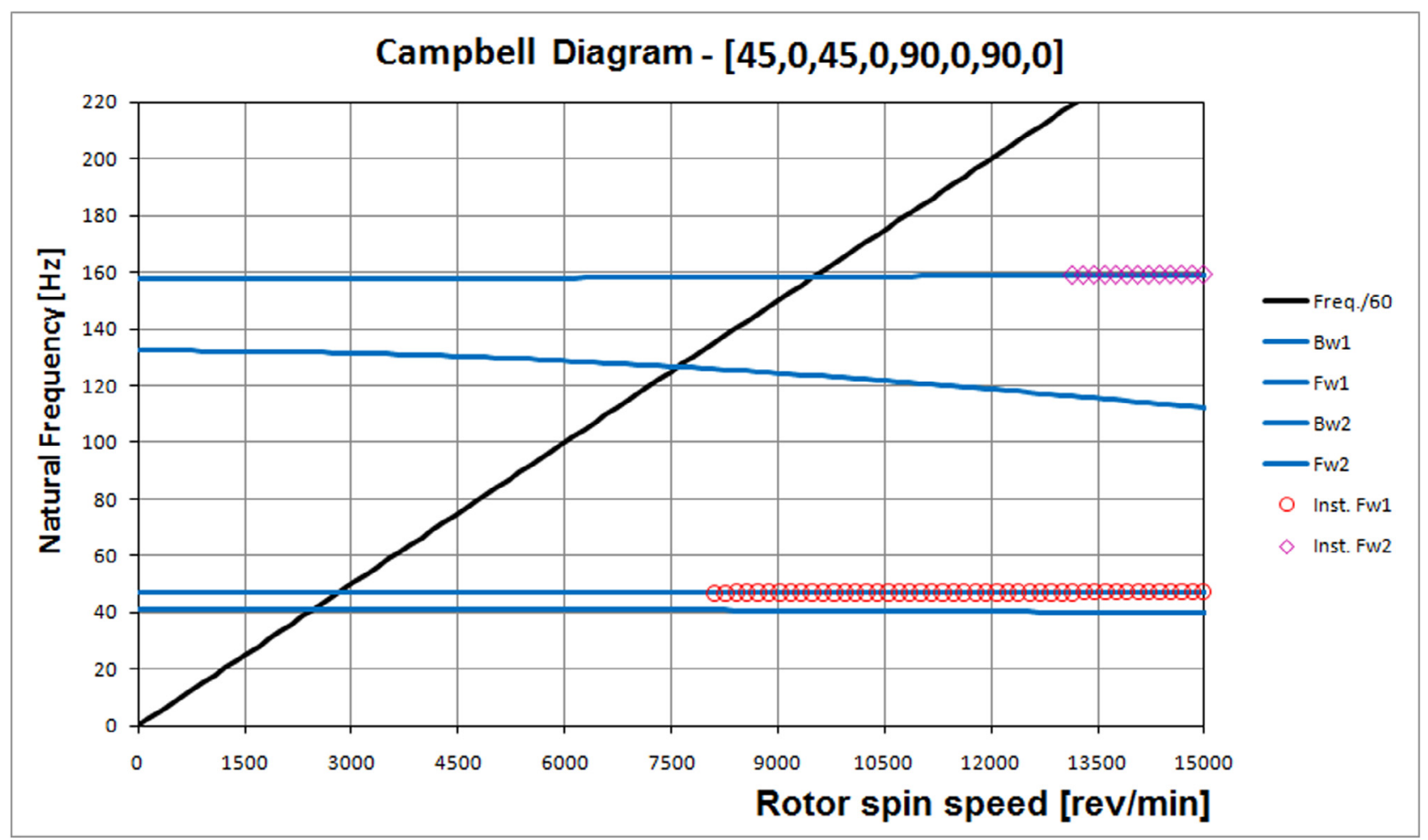

Fig. 10. Campbell diagram and instability regions for layup $[45,0,45,0,90,0,90,0]$.

modulus of elasticity $\left(E_{x}=172.7 \mathrm{GPa}\right)$. Although the angle-ply layup in Fig. 11 has less damping $\left(\psi_{\mathrm{t}}=4.693 \%\right)$ than the off-axis layup in Fig. $9\left(\psi_{\mathrm{t}}=5.266 \%\right)$, the off-axis configuration has better stability because its elastic modulus $\left(E_{\mathrm{x}}=13.91 \mathrm{GPa}\right)$ is lower than that of the angle-ply configuration $\left(E_{x}=45.31 \mathrm{GPa}\right)$. This analysis demonstrates that it is possible to tune the dynamic behavior of the rotor. 


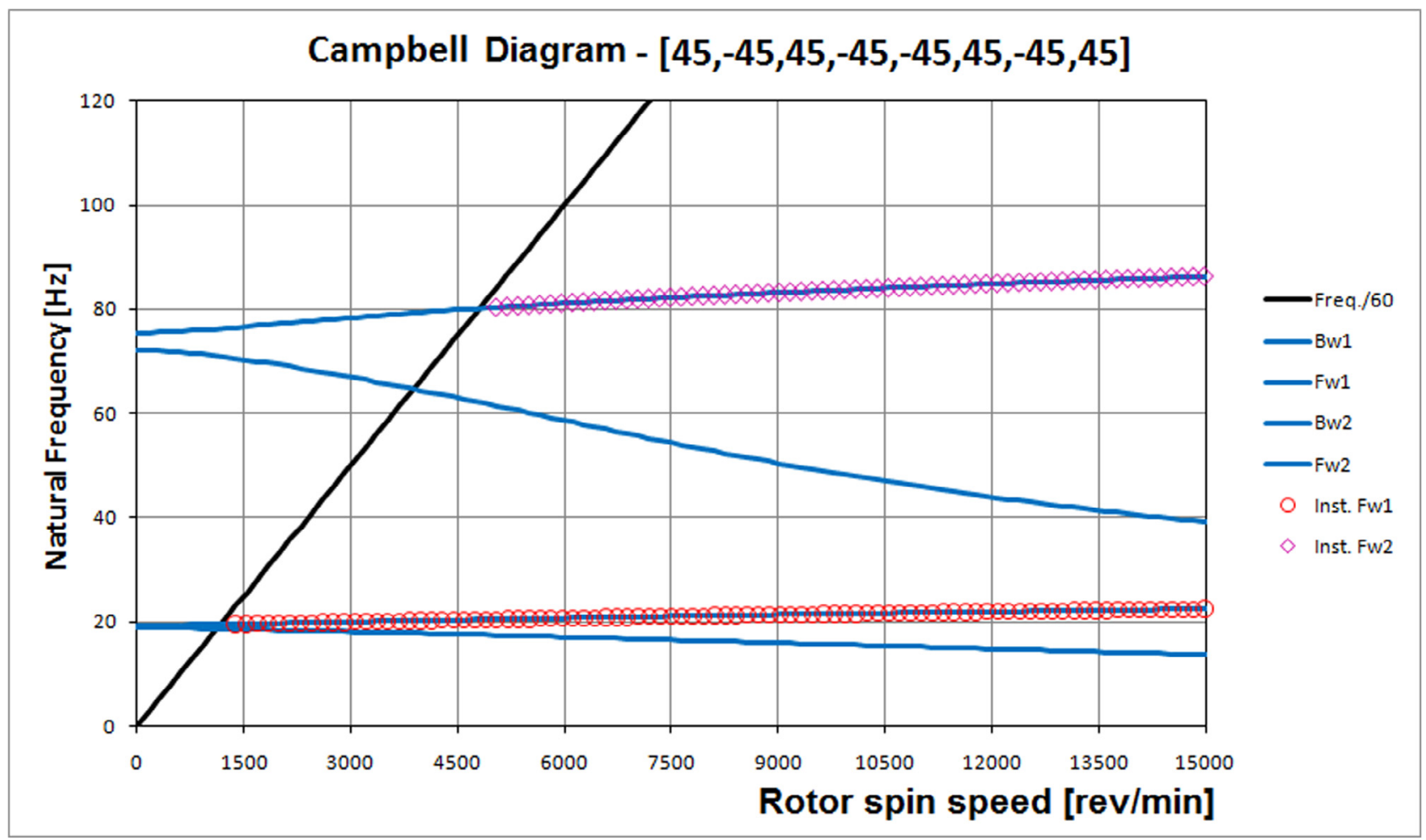

Fig. 11. Campbell diagram and instability regions for layup $[45,-45,45,-45,-45,45,-45,45]$.

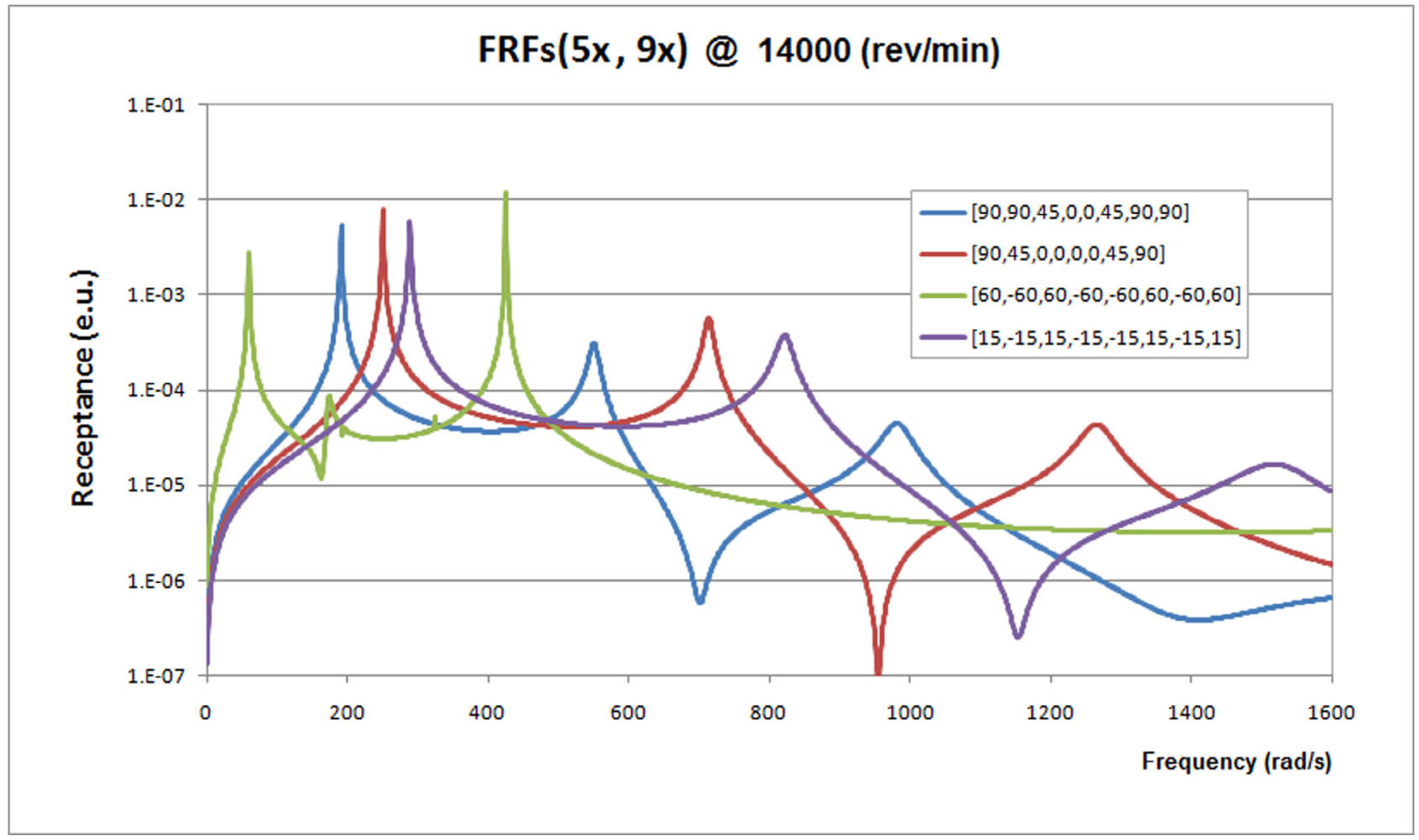

Fig. 12. FRF between nodes 5 and 9 at $14,000 \mathrm{rev} / \mathrm{min}$.

\subsection{Layup influence on FRF}

In this section, the simulation results show the influence of the shaft layup on the FRF. The results plotted in Figs. 12 and 13 were calculated using Eq. (37). The titles of the figures describe the parameters used in the analysis, such as the input and output nodes and the rotor spin speed. The figure legends show the layup used for each FRF. 


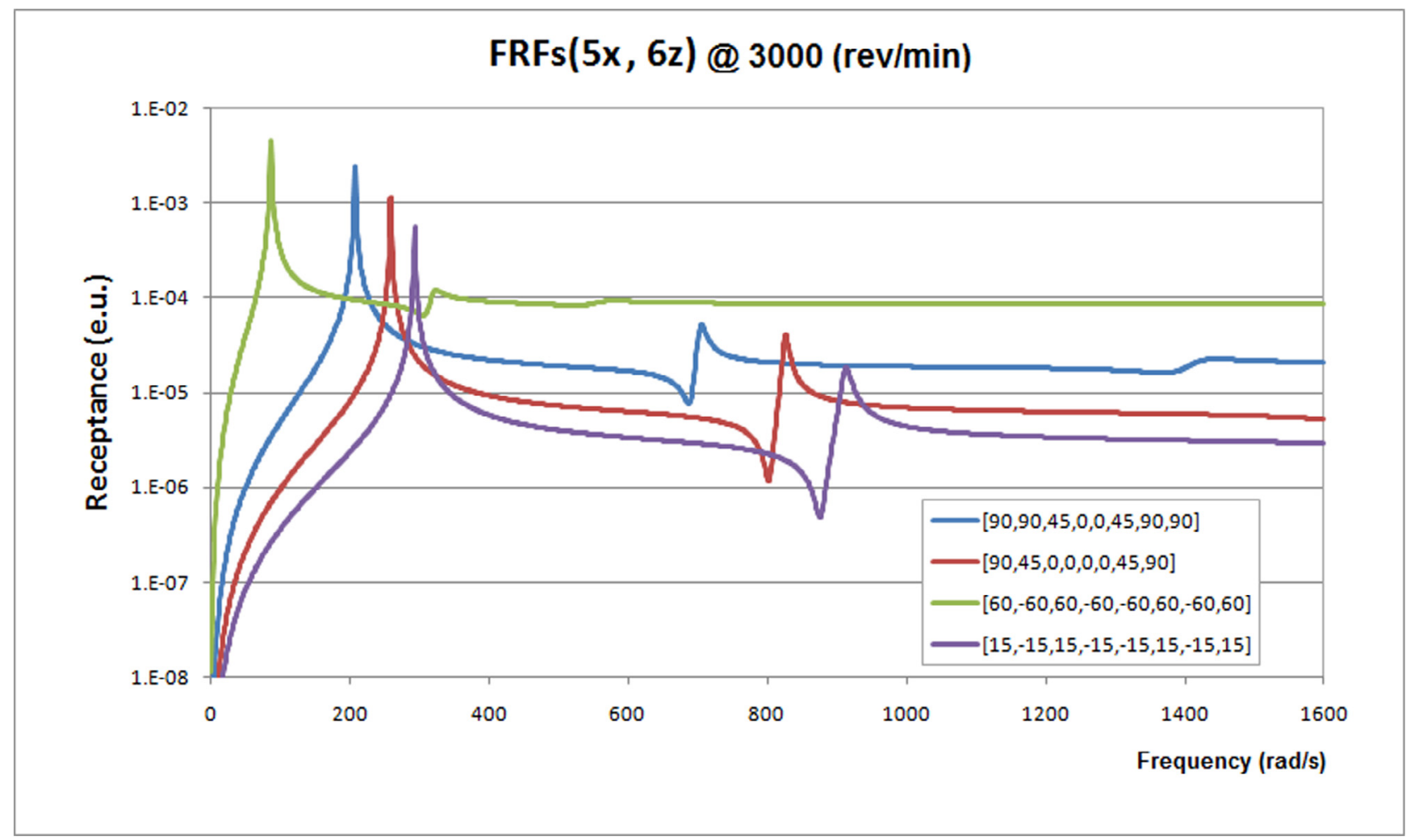

Fig. 13. FRF between nodes 5 and 6 at $3000 \mathrm{rev} / \mathrm{min}$.

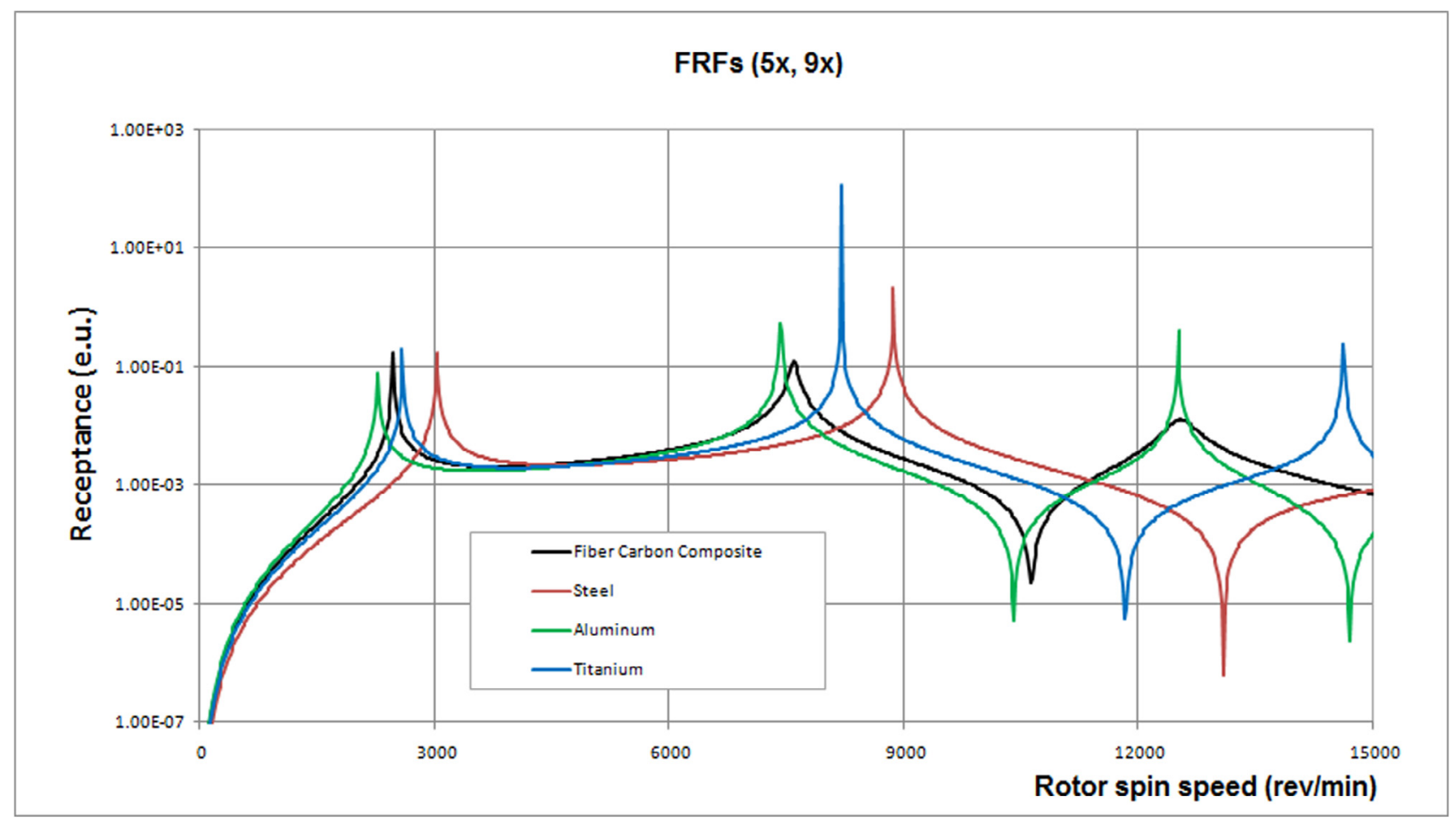

Fig. 14. FRF between nodes 5 and 9.

The main finding of this analysis is the possibility to control the rotor deflection based on layup choice.

\subsection{Influence of shaft material on FRF}

Four rotors with different shaft materials were simulated. Using the rotor model shown in Fig. 6, the FRFs were evaluated between nodes 5 and 9 (see, Fig. 14). The shaft materials simulated were titanium, aluminum, steel and carbon fiber composite. Their properties are shown in Table 6.

In addition to the variation in the natural frequency from the use of the different materials, there was variation in the receptance amplitude. The composite shafts had smaller amplitudes due to the greater damping experienced. 
Table 6

Shaft materials.

\begin{tabular}{lllll}
\hline \multirow{2}{*}{ Material } & $\mathrm{E}_{1}$ & $\mathrm{G}_{12}$ & $\psi \mathrm{t}$ & $\rho$ \\
\cline { 2 - 5 } & {$[\mathrm{GPa}]$} & {$[\mathrm{GPa}]$} & {$[\%]$} & {$\left[\mathrm{kg} / \mathrm{m}^{3}\right]$} \\
\hline Titanium & 107 & 39.9 & - & 4507 \\
Steel & 210 & 80.8 & - & 7800 \\
Aluminum & 71 & 26.5 & - & 2700 \\
HMS carbon-epoxy (DX-210) $\left[90,45,0_{2}\right]_{\mathrm{S}}$ & 92.8 & 11.3 & 0.757 & 1446 \\
\hline
\end{tabular}

\section{Conclusion}

Simulations were performed to demonstrate the influence of the layup on the shaft equivalent mechanical properties and therefore the effects on the rotor dynamic behavior. The results show the potential of the methodologies applied and the flexibility in the use of composite materials, which enables the optimization of the mechanical properties and improves the rotor dynamic behavior.

The methodology used to predict the mechanical properties of the composite shafts demonstrates that there are multiple design alternatives, as well as many possible combinations, of the elastic modulus and the SDC. This versatility demonstrates the suitability of composite shafts for different designs.

The methodology for the dynamic analysis of rotors with damping shafts requires more analysis than conventional rotors because rotors with damping shafts must be evaluated for each rotor spin speed. In this paper, only the frequency dependency of the viscoelastic materials was evaluated; however, there are other important variables. The most important is the temperature, which can modify the mechanical properties.

Future studies should focus on the experimental evaluation of rotors to verify the simulation results presented in this paper.

\section{References}

[1] Qatu MS, Iqbal J. Transverse vibration of a two-segment cross-ply composite shafts with a lumped mass. Compos Struct 2010;92:1126-31.

[2] Hajianmalek M, Qatu MS. Transverse vibration analysis of generally laminated two-segment composite shafts with a lumped mass using generalized differential quadrature. J Vib Control 2012;19(13):2013-21.

[3] Chang C-Y, Chang M-Y, Huang JH. Vibration analysis of rotating composite shafts containing randomly oriented reinforcements. Compos Struct 2004:63:21-32.

[4] Paykani A, Khoshravan MR. Design of a composite drive shaft and its coupling for automotive application. J Appl Res Technol 2012;10:826-34.

[5] Dharmadhikari SR, Mahakalkar GS, Giri JP, Khutafale ND. "Design and analysis of composite drive shaft using Ansys and genetic algorithm" a critical review. Int J Mod Eng Res (IJMER) 2013;3(1):490-6.

[6] Arun M, Vinoth KS. Design and development of laminated aluminum glass fiber drive shaft for light duty vehicles. Int J Innov Technol Exploring Eng (IJITEE) May 2013;2(6):157-65.

[7] Talib ARA, Ali A, Badie MA, Lah NAC, Golestaneh AF. Developing a hybrid, carbon/glass fiber-reinforced, epoxy composite automotive drive shaft. Mater Des 2010;31:514-21.

[8] Badie MA, Mahdi E, Hamouda AMS. An investigation into hybrid carbon/glass fiber reinforced epoxy composite automotive drive shaft. Mater Des 2011:32:1485-500.

[9] DeValve C, Pitchumani R. A numerical analysis of carbon nanotube-based damping in rotating composite structures. Compos Struct 2013;103:18-26.

[10] Sino R, Baranger TN, Chatelet E, Jacquet G. Dynamic analysis of a rotating composite shaft. Compos Sci Technol 2008:68:337-45.

[11] Treviso A, Genechten BV, Mundo D, Tournour M. Damping in composite materials: properties and models. Compos: Part B 2015;78:144-52.

[12] Sun J, Arteaga IL, Kari L. Dynamics modeling of a multilayer rotating blade via quadratic layerwise theory. Compos Struct 2013;99:276-87.

[13] Shin ES. Stability of a supercritical composite shaft supported by non-rigid beam. In: 15th international congress on sound and vibration (ICSV15), vol. 1 , Daejon, July 2008. p. 1323-9.
[14] Lee SK, Kim MW, Park CJ, Chol MJ, Kim G, Cho J-M, et al. Effect of fiber orientation on acoustic and vibration response of a carbon fiber/epoxy composite plate: natural vibration mode and sound radiation. Int J Mech Sci 2016;117:162-73.

[15] Gubran HBH, Gupta K. The effect of stacking sequence and coupling mechanisms on the natural frequencies of composite shafts. J Sound Vib 2005;282:231-48.

[16] Zhou XQ Yu DY, Shao XY, Zhang SQ, Wang S. Research and applications of viscoelastic vibration damping materials: a review. Compos Struct 2016;136:460-80

[17] Biswal M, Sahu SK, Asha AV. Vibration of composite cylindrical shallow shells subjected to hygrothermal loading-experimental and numerical results. Compos: Part B 2016;98:108-19.

[18] Qin Y, Li X, Yang EC, Li YH. Flapwise free vibration characteristics of a rotating composite thin-walled beam under aerodynamic force and hygrothermal environment. Compos Struct 2016;153:490-503.

[19] Teter A, Gawryluk J. Experimental modal analysis of a rotor with active composite blades. Compos Struct 2016;153:451-67.

[20] Herman AP, Orifici AC, Mouritz AP. Vibration modal analysis of defects in composite T-stiffened panels. Compos Struct 2013;104:34-42.

[21] Han SH, Cho EJ, Lee HC, Jeong K, Kim SS. Study on high-speed RTM to reduce the impregnation time of carbon/epoxy composites. Compos Struct $2015 ; 11: 50-8$

[22] Daniel IM, Ishai O. Engineering mechanics of composite materials. Oxford New York: Oxford University Press; 1994.

[23] Adams RD, Maheri MR. Dynamic flexural properties of anisotropic fibrous composite beams. Compos Sci Technol 1994;50:497-514.

[24] Hajianmaleki M, Qatu MS. A rigorous beam model for static and vibration analysis of generally laminated composite thick beams and shafts. Int J Veh Noise Vib 2012;8(2):166-84.

[25] Song X, Han Q Zhai J. Vibration analyses of symmetrically laminated composite cylindrical shells with arbitrary boundaries conditions via Rayleigh-Ritz method. Compos Struct 2015;134:820-30.

[26] Ghafari E, Rezaeepazhand J. Vibration analysis of rotating composite beams using polynomial based dimensional reduction method. Int J Mech Sci 2016;115-116:93-104.

[27] Ni RG, Adams RD. A rational method for obtaining the dynamic mechanical properties of laminate for predicting the stiffness and damping of laminated plates and beams. Composites 1984;15(3).

[28] Hajianmaleki M, Qatu MS. Static and vibration analyses of thick, generally laminated deep curved beams with different boundary conditions. Compos: Part B 2012;43:1767-75.

[29] Abramovich H, Govich D, Grunwald A. Damping measurements of laminated composite materials and aluminum using the hysteresis loop method. Prog Aerosp Sci 2015;78:8-18.

[30] Zorzi ES, Nelson HD. Finite element simulation of rotor-bearing systems with internal damping. J Eng Power ASME 1977.

[31] Genta G. Dynamics of rotating systems. IN: Mechanical engineering series Springer, 674 f.; 2005.

[32] Chouksey M, Dutt JK, Modak SV. Modal analysis of rotor-shaft system under the influence of rotor-shaft material damping and fluid film forces. Mech Mach Theory 2012;48:81-93.

[33] Jun L, Zhen W, Xiangshao K, Xiaobin L, Weiguo W. Comparison of various shear deformation theories for free vibration of laminated composite beams with general lay-ups. Compos Struct 2014;108:767-78.

[34] Mehdi H, Mohamad SQ. Vibrations of straight and curved composite beams: a review. Compos Struct 2013;100:218-32.

[35] Espíndola JJ, Floody SE. On the modeling of metal - elastomer composite structures: a finite element method approach. Appl Mech Am PACAM IV 1999;8:1342-55.

[36] Espíndola JJ, Bavastri CA. An efficient concept of transmissibility for a general equipment isolation system. In: DETC'97/VIB-4120. ASME design engineering technical conferences, Sacramento, California, v. CD ROM. P. CD-CD.

[37] Lalanne M, Ferraris G. Rotordynamics prediction in engineering. second ed. Wiley; 1997. $254 \mathrm{f}$.

[38] Wang Y, Inman DJ. Finite element analysis and experimental study on dynamic properties of a composite beam with viscoelastic damping. J Sound Vib 2013;332:6177-91.

[39] Su Y-Y, Gao K-L. Analytical model for adhesively bonded composite panelflange joints based on the Timoshenko beam theory. Compos Struct 2014;107:112-8.

[40] Aksencer T, Aydogdu M. Flapwise vibration of rotating composite beams. Compos Struct 2015;134:672-9.

[41] Torabi K, Shariati-Nia M, Heidari-Rarani M. Experimental and theoretical investigation on transverse vibration of delaminated cross-ply composite beams. Int J Mech Sci 2016;115-116:1-11.

[42] Chortis DI, Varelis DS, Saravanos DA. Prediction of material coupling effect on structural damping of composite beams and blades. Compos Struct 2012;94:1646-55.

[43] Montagnier O, Hochard C. Dynamics of a supercritical composite shafts mounted on viscoelastic supports. J Sound Vib 2014;333:470-84. 